\title{
THREE SPORADIC CASES OF INFECTION DUE TO SALMONELLA TYPE DUBLIN
}

BY

\author{
H. ROSS SOUPER, M.A., M.D., J. SMITH, M.D., D.Sc., D.P.H., \\ and J. A. STEPHEN, M.A., M.B., Ch.B., D.P.H. \\ (From the City Hospital, Aberdeen.)
}

In 1926 Pesch reported a case of meningitis due to a Gaertner-like organism. The culture was examined by Bruce White (1926) and was found by him to be identical with an organism sent to him by Dr. J. W. Bigger. This Dublin strain was isolated from a case of fatal fever supervening after a kidney operation.

Bruce White (1929) has exhaustively examined the serology of the Dublin strain. He has shown that the somatic antigens of the Dublin type and of S. enteritidis are identical, but that on the other hand the flagellar antigens differ ; and he represents these antigens of $\mathrm{S}$. enteritidis as $\mathrm{R}, \mathrm{Pl}$, and $\mathrm{P} 2$, and the same antigens of the Dublin type as R, Pl and P3. Thus, when S. enteritidis serum is saturated with the Dublin type, or Dublin serum with $\mathrm{S}$. enteritidis, there remains in each case a definite residue of flagellar agglutinins for the homologous organism.

Smith and Scott (1930) reported the clinical findings in two cases, and the bacteriological findings only in one case, of infection due to this organism. In addition all available strains of Gaertner-like organisms were examined with the result that the Dublin type of Salmonella was found to have been the causative agent in a milk epidemic in Newcastle in 1910, and in outbreaks of food poisoning in Nottingham in 1919, and in London in 1921; the organism had also been isolated from a case of septicæmia by Gregg and Hayes in 1921 . Further, this Dublin type of Salmonella was found to be identical with certain 'paracolon bacilli' isolated by Jensen (1913) from cases of calf dysentery. From the available evidence Smith and Scott suggested that the Dublin type is of bovine habitat, and that cows' milk is the vehicle of infection.

\section{Present Cases.}

It seems advisable, therefore, to give the clinical histories and bacteriological findings in three further cases of infection due to Salmonella type Dublin.

Case 1.-I. L., a boy aged 5 years had been ill at home with an undiagnosed pyrexial condition for three weeks. On Feb. 12th, 1929, he was seen by one of us (H. R. S.) on account of symptoms suggesting a mastoiditis. On examination it was found that he had a profuse bilateral otorrhœa and that there was marked œdema over the right mastoid process. There was an indefinite history of ear trouble for years. The patient was removed to a nursing home, and a cortical mastoid operation was immediately performed, pus being found throughout the mastoid cells. There was some improvement in the general condition following the operation; the temperature on the following morning was normal, but in the evening it rose to $99.5^{\circ}$ and the pulse rate increased proportionately. The patient's temperature continued to show 
morning remissions (Chart 1), and on 17 th $30 \mathrm{c.cm}$. of scarlet fever streptococcal antitoxin was given intravenously and a similar amount was given on 19th. On 18th the right lateral sinus was explored and found free from clot. A left cortical mastoid operation was performed and a small amount of pus found in the antrum and upper cells. The condition did not respond either to serum treatment or to the second operation. The temperature and pulse rate increased and rigors became frequent, and the general condition of the patient deteriorated. On March 8th slight jaundice was evident, and during the following day the patient became delirious and died on the morning of March 10th. A blood culture made on Feb. 19th showed a Gramnegative, non-lactose fermenting, motile bacillus ; and a sample of fæc:s obtained two days later showed a similar organism. Cultures made from pus obtained from the ear showed streptococcus hæmolyticus and staphylococci.

CHART 1.

Temperature Chart in Case 1.

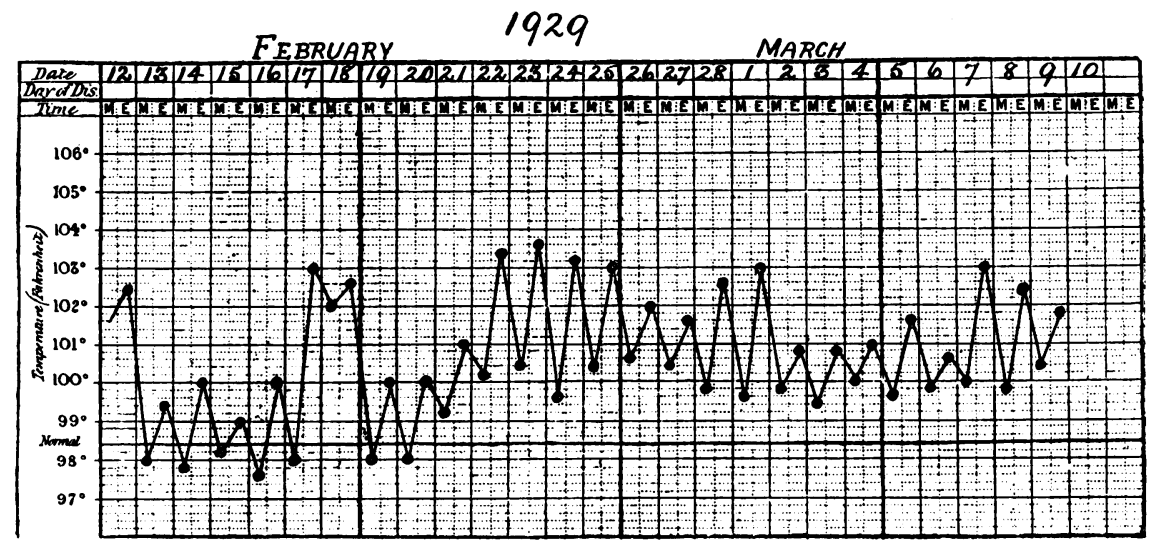

It appears evident, therefore, that this patient had had a septicæmia for some weeks, and as a result of the lowering of the patient's resistance an acute exacerbation of the chronic infection of the middle ears had occurred.

Case 2.-N. M., a female infant aged 11 weeks, was admitted March 29th, 1929, to hospital suffering from vague digestive upset. On admission the temperature was rormal, but on the following day it rose to $102 \cdot 2^{\circ}$, and three days later was again normal. During the initial stages of the illness the child vomited frequently, and although there was no actual diarrhoea the stcols were green. Clinical examination showed no signs of any definite lesion in chest, abdomen, or in nervous system. After the subsidence of the fever the convalescence was uneventful. On May 22nd a small amount of blood was obtained for blood culture, but this specimen remained sterile. On the same day the fæces and urine were examined, and a Salmonella-like organism was obtained from the urine only. On May 27 th the blood, urine and fæces were again examined, and the same organism was obtained from the urine. Finally, the fæces and urire were examined for the third time on June 3rd, but ro pathogenic types were obtained.

Case 3. F. D., a female child had been born in hospital on Feb. 21st, 1929. The infant progressed favourably until June 6 th when there was a slight rise in temperature, and it was noticed that she had developed a hard dry cough, but examination of the chest gave no indication of any intra-pulmonary lesions. On June 8th the temperature again reached $99^{\circ}$ and on the following day rose to $102 \cdot 5^{\circ}$, and on this day examination of chest showed dullness on percussion over the middle of left lung posteriorly and auscultation showed a raising of pitch of the breath sounds. On the following day the chest signs showed no further change, but the child now showed obvious signs of meningitis, there being definite head retraction, bulging of the fontanelle, a positive Kernig, and an internal squint of the left eye. The clinical condition of the infant became rapidly worse, and she died on June 11th.

For bacteriological examination the only specimen obtained from this case was the cerebrospinal fluid taken on Jure 19th. This specimen was a turbid fluid and a qua!itative chemical 
examination showed a marked increase above normal of globulin and a decrease in tho sugar content. Microscopic examination showed 540 cells per c.mm., 68 per cent. of the cells being polymorphonuclear leucocytes and 32 per cent. lymphocytes. Microscopic examination also showed numerous Gram-negative bacilli. Cultural examination showed numerous colonies of a Gram. negative bacillus which later was found to be a non-lactose motile Salmonella-like organism.

CHART 2.

Temperature chart in Case 3.

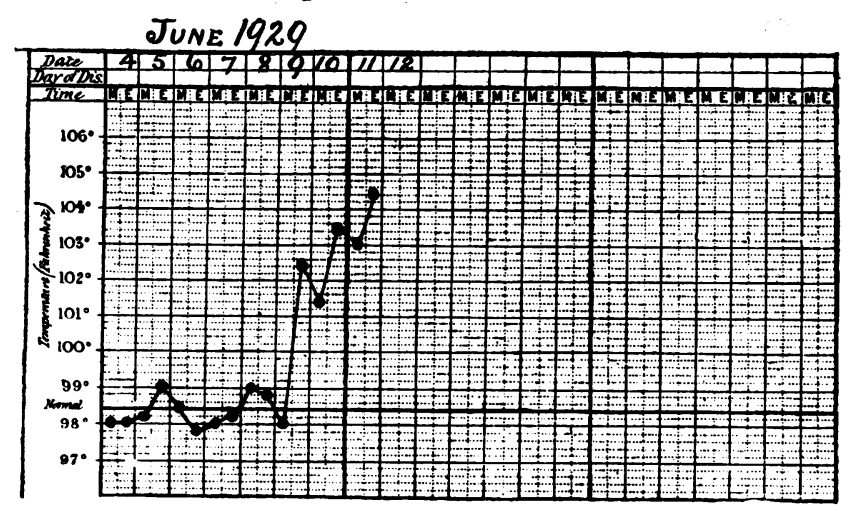

Bacteriological examination of strains.-The fermentation reactions of three strains are given in Table 1, and from this it will be seen that all strains gave reactions similar to those produced by $\mathrm{S}$. enteritidis Gaertner with the exception that the isolated strains produced no acid or gas in arabinose. None of the strains produced indol, but all produced sulphide in lead acetate agar, and all produced an alkaline reaction in litmus milk. For the serological classification sera were prepared by immunizing rabbits with formalin-killed cultures of the three strains for the production of ' $\mathrm{H}$ ' or flagellar agglutinins and with cultures heated at $100^{\circ} \mathrm{C}$. for the ' $\mathrm{O}$ ' or somatic agglutinins. The results of the absorption tests, given in Table 2, show that absorption of $S$. enteritidis ' $H$ ' serum by the Dublin type reduced the titre slightly and the absorption of the Dublin type ' $H$ ' sera by $S$. enteritidis did the same. All the isolated strains absorbed the ' $\mathrm{H}$ ' agglutinins from ' $\mathrm{H}$ ' Dublin antiserum. On the other hand all the Dublin type strains completely absorbed the agglutinins from the $\mathrm{S}$. enteritidis ' $\mathrm{O}$ ' somatic serum, and $\mathrm{S}$. enteritidis similarly absorbed the agglutinins from all the Dublin type ' $\mathrm{O}$ ' sera.

TABLE 1.

Fermentation tests.

\begin{tabular}{|c|c|c|c|c|c|c|c|c|c|c|c|c|c|c|c|c|c|c|c|c|}
\hline & \multicolumn{7}{|c|}{ Monosaccharides } & \multirow{2}{*}{\multicolumn{3}{|c|}{ Disaccharides }} & \multirow{2}{*}{ 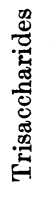 } & \multirow{2}{*}{\multicolumn{2}{|c|}{$\begin{array}{l}\text { Polysacch- } \\
\text { arides }\end{array}$}} & \multirow{2}{*}{\multicolumn{2}{|c|}{ Alcohols }} & \multirow{2}{*}{\multicolumn{2}{|c|}{ Glucoside }} & \multirow{3}{*}{ 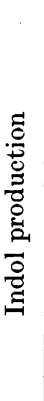 } & \multirow{3}{*}{ 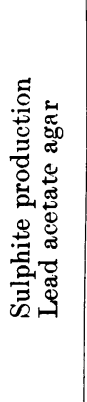 } & \multirow{3}{*}{ 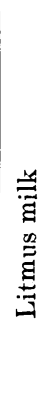 } \\
\hline & \multicolumn{4}{|c|}{ IIexose } & \multicolumn{2}{|c|}{ Pentose } & \multirow{2}{*}{ 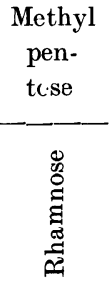 } & & & & & & & & & & & & & \\
\hline & 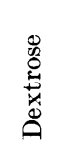 & 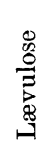 & 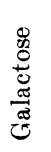 & 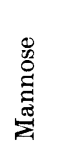 & 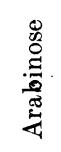 & 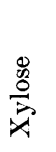 & & 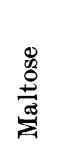 & 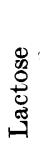 & 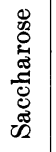 & 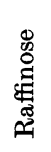 & 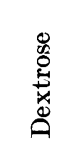 & $\underset{\Xi}{\Xi}$ & 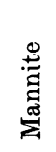 & $\frac{\stackrel{0}{0}}{0}$ & 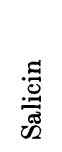 & 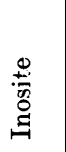 & & & \\
\hline S. enteritidis & $\mathrm{AG}$ & $\mathrm{AG}$ & $\mathrm{AG}$ & $\mathrm{AG}$ & $\mathrm{AG}$ & $\mathrm{AG}$ & $A G$ & $\mathrm{AG}$ & $\mathrm{O}$ & 0 & $\mathrm{O}$ & $\mathrm{O}$ & & $\mathrm{AG}$ & $\mathrm{AG}$ & $\mathrm{O}$ & & $\mathrm{O}$ & Black & Alk. \\
\hline S. Dublin ... & ", & , & , & , & & , & ", & ", & $\mathrm{O}$ & O & $\mathrm{O}$ & & 0 & , & , & $\mathrm{O}$ & & $\mathrm{O}$ & ", & , \\
\hline Case $1 \quad \ldots$ & , & , & , & , & $\mathrm{O}$ & , & , & ", & $\mathrm{O}$ & $\mathrm{O}$ & O & & & , & , & $\mathrm{O}$ & & 0 & , & , \\
\hline Case 2 & , & , & , & , & $\mathrm{O}$ & , & , & , & O & O & O & $\mathrm{O}$ & $\mathrm{O}$ & , & , & $\mathrm{O}$ & $\mathrm{O}$ & 0 & , & , \\
\hline Case $3 \quad \ldots$ & , & , &, & , & O & ", & , & ", & & $\mathrm{O}$ & 0 & & & ", & , & $\mathrm{O}$ & & 0 & , & , \\
\hline
\end{tabular}


TABLE 2.

ABSORPTION OF AGGLUTININS.

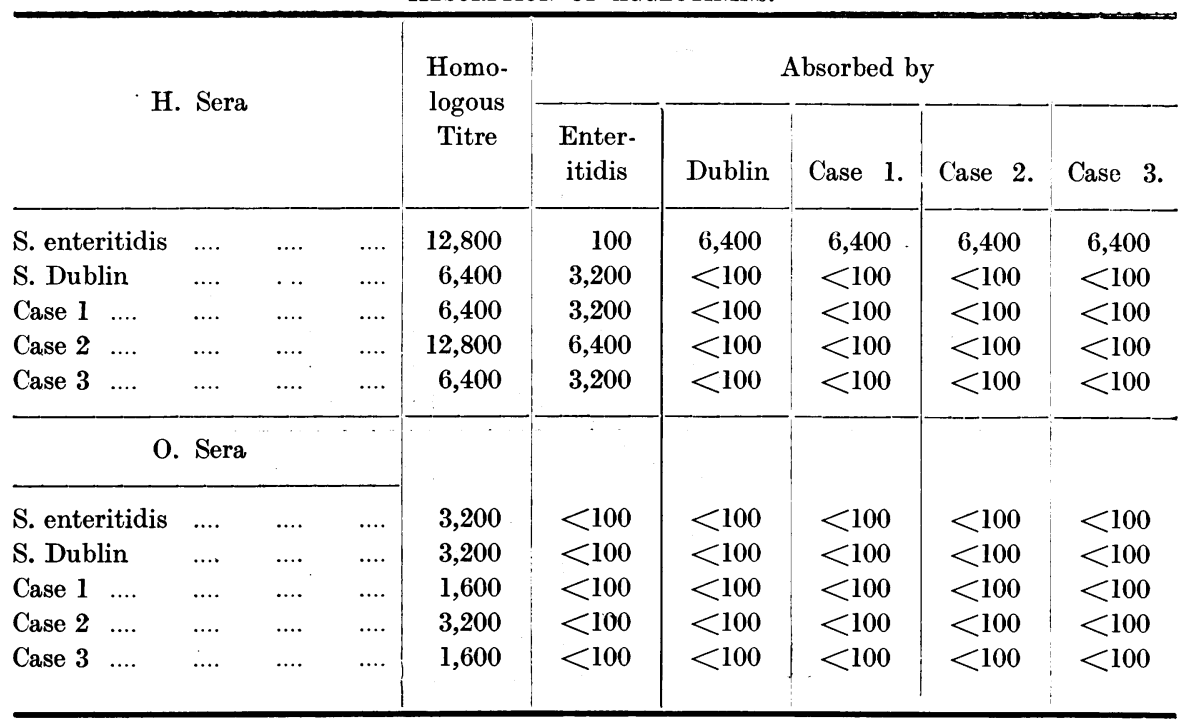

Discussion.

Three cases of infection due to Salmonella type Dublin have been described in detail, making a total of five cases encountered in Aberdeen since 1925. The first recognized case occurred in an adult male aged 38, the second in a female child aged 2 years, and of the three cases now recorded, two occurred in infants, and one in a boy aged 5 years. All cases must have had a septicæmia, since in three cases the organism was isolated from the blood, in one case in which the blood cultures were inadequate the organism was isolated from the urine, and in the fifth case from the cerebro-spinal fluid which, presumably, became infected secondarily from the blood. Two cases out of the five died.

In four of the cases the home conditions were investigated, but no other case of illness had occurred in any other member of the various families. Further, the fifth case actually occurred in a hospital ward in which there were 18 other infants. Here a complete investigation was made of the fæces and urine of 5 members of the nursing staff and of all other patients in the ward, but the results were entirely negative. If milk had been the vehicle of infection in the fifth case, then only one case occurred out of a total hospital population of some 350 children and adults.

\section{Summary.}

The clinical and bacteriological findings in three cases of infection due to Salmonella type Dublin are described. Since 1925 a total of five cases of infection due to this organism has been encountered in Aberdeen.

One of the authors (J.S.) is indebted to the Medical Research Council for a personal grant.

\section{References.}

Gregg, R. G. S., \& Hayes, P., J. R. Army Med. Corps, Lond., 1921, XXXVII, 64.

Jensen, C. O., Kolle-Wassermann's Handb. d. path. mikroorg., 1913, VI, 121.

Pesch, K. C., Zentralbl. Bakt. Abt. i. Orig., 1926, XCVIII, 22.

Smith, J., \& Scott, W. M., J. Hygiene, Camb., 1930, XXX, 32.

White, P. Bruce, Med. Res. Coun., Lond., 1926, Sp. Rep., 103.

White, P. Bruce, J. Hygiene, Camb., 1929. XXIX, 443. 